\title{
Effects of Ankle Self-Mobilization with Movement Intervention on Ankle Dorsiflexion Passive Range of Motion, Timed Up and Go Test, and Dynamic Gait Index in Patients with Chronic Stroke
}

\author{
Donghwan Parka \\ ${ }^{a}$ Department of Physical Therapy, College of Health Sciences, Kyungnam University
}

\begin{abstract}
Objective: Patients with stroke generally diminished ankle range of motion, which decreases balance and walking ability. This study aimed to determine the effect of ankle self-mobilization with movement (s-MWM) on ankle dorsiflexion passive range of motion, timed up and go test, and dynamic gait index in patients with chronic stroke.
\end{abstract}

Design: Randomized controlled trial design

Methods: Twenty-four post-stroke patients participated in this study. The participants were randomized into the control $(\mathrm{n}=12)$ and self-MWM groups $(\mathrm{n}=12)$. Both groups attended standard rehabilitation therapy for 30 minutes per session. In addition, self-MWM group was performed 3 times per week for 8 weeks. All participants have measured ankle dorsiflexion passive range of motion, timed up and go test, and dynamic gait index in before and after the intervention.

Results: After 8 weeks of training, self-MWM group showed greater improvement in ankle dorsiflexion passive range of motion, timed up and go test, and dynamic gait index than in the control group $(\mathrm{p}<0.05)$. Further, self-MWM group had significantly improvement in all dependent variables compared to the pre-test $(\mathrm{p}<0.05)$.

Conclusions: Our investigation demonstrates that self-MWM is beneficial for improving functional ability. Also, self-MWM was superior to control with respect to improving ankle dorsiflexion passive range of motion, timed up and go test, and dynamic gait index.

Key Words: Self-mobilization with movement, Stroke, Range of motion, Dynamic gait index

서론

뇌졸중과 같은 신경학적 손상은 일반적으로 하지의 근 력 감소, 운동조절 능력의 저하가 나타나 균형과 보행 능 력 장애로 이어지며 뇌졸중 환자의 일상생활동작을 수행 하는데 어려움을 미치는 질환이다[1,2]. 정상적인 보행을 위해서는 $10^{\circ} \sim 15^{\circ}$ 범위의 발목의 수동적 배측 굴곡 관절 가동범위(dorsiflexion passive range of motion, DF-PROM) 가 필요하며, 뇌졸중 환자는 건강한 사람에 비해 약 $50 \%$ 의 DF-PROM를 나타낸다[3, 4]. 또한, 뇌졸중 환자의 제 한된 DF-PROM은 균형과 독립적인 보행에 영향을 미쳐 낙상의 위험도를 높이는 원인이 된다 $[5,6]$.

최근 뇌졸중 환자의 DF-PROM, 균형 및 보행 능력을
개선시키기 위해 키네지오 테이핑(kinesio taping), 스트 레칭, 발목 보조기(ankle-foot orthosis) 등의 치료적 중재 방법들이 적용되어지고 있다[7-9]. Gao 등 [7]은 뇌졸중 환자 10 명을 대상으로 60 분간 발목 스트레칭을 적용한 결과 대조군과 비교한 결과 DF-PROM이 증가와 함께 발 목 경직(joint stiffness)의 감소가 나타났으며, de Wit 등 [8]은 40세부터 75 세의 만성 뇌졸중 환자 28 명을 대상으 로 발목 보조기를 적용한 결과 보행 속도와 일어서서 걷 기 검사(timed up and go test, TUG test) 그리고 계단 오르기 능력이 개선되어 나타났다. 또한, Park과 Cynn [9]은 만성 뇌졸중 환자를 대상으로 거골(talus)에 안정화 테이핑을 적용하였고, 그 결과 DF-PROM, TUG test, 보 행 속도와 낙상위험도의 개선이 나타났다. 
움직임을 동반한 발목 가동술(Mobilization with movement, MWM)은 물리치료사의 손을 이용하여 발 목을 고정시키고, 환자의 손상측 발목을 체중지지 상태 에서 거골을 후방 활주시키며 환자의 능동적인 움직임 을 통해 발목의 배측 굴곡(dorsiflexion)을 증가시킨다 $[10,11]$. 그러나 기존의 MWM은 거골의 활주를 위해 치료사의 손을 통해 환자의 발목을 고정시켜야 하는 단점이 있으며, 환자가 독립적으로 수행하는데 어려움 이 있다. $\mathrm{MWM}$ 의 적용을 위해 치료사의 손이 필요하 다는 단점을 보완하기 위해 제한된 발목의 DF-PROM 을 가진 정상인을 대상으로 한 스트랩(strap)을 이용한 자가-MWM(self-MWM)이 연구되어 지고 있으며, self-MWM은 환자의 능동적인 움직임 동안 거골의 활 주와 함께 반복적인 배측 굴곡을 만들어 관절가동범위 를 증가시킨다[12]. 또한, 뇌졸중 환자를 대상으로 한 발목의 MWM 연구에서는 5주간의 발목 $\mathrm{MWM}$ 적용 후 발목의 근력, 움직임, 그리고 체중지지 능력이 개선 되어 나타났다[13]. 따라서 self-MWM은 뇌졸중 환자 의 발목의 DF-PROM 및 기능개선을 위한 효과적인 운 동프로그램이 될 수 있다.

이러한 self-MWM의 장점에도 불구하고 뇌졸중환자를 대상으로 한 연구는 부족한 실정이다. 이에 본 연구는 self-MWM의 적용이 만성 뇌졸중 환자의 DF-PROM, TUG test 그리고 동적 보행지수(dynamic gait index, DGI)에 미치는 영향을 알아보고자 한다.

\section{연구방법}

\section{연구대상}

본 연구는 인천 $\mathrm{K}$ 병원에서 입원하여 치료 중인 만성 뇌졸중 환자 가운데 본 연구의 목적에 충족되는 환자를 대상으로 실시하였다. 본 연구에서는 6명의 지원자를 대 상으로 예비 검사가 수행되었으며, DGI 예비 검사결과를 토대로 G-power software(version 3.1.2; Franz Faul, University of Kiel, Kiel, Germany)를 사용하여 유의 수 준(0.05), 검정력(0.80) 및 효과 크기(1.19)로 설정하였다. 검정력 분석결과 그룹 당 10 명의 대상자를 필요로 하였으 며, 총 24 명의 만성 뇌졸중 환자가 본 연구에 자발적으로 참여하였다. 대상자 선정 조건은 1) 허혈성 또는 출혈성 뇌졸중으로 진단을 받고 6개월 이상 경과한자, 2) 마비측 발목의 관절가동범위가 $8^{\circ}$ 미만인 자, 3) 보조 장비 없이 $10 \mathrm{~m}$ 이상 보행 가능한 자, 4) 스스로 체중지지자세가 가 능한자, 5) 한글판 간이 정신상태 검사가 24점 이상인자 를 대상으로 하였으며, 제외조건은 연구에 영향을 미칠 수 있는 정형외과적 질환이 있거나 관절가동술의 금기증
이 있는 자로 하였다. 본 연구를 시작하기 전에 실험 참여 에 자발적으로 동의하고 연구 동의서에 직접 서명한 대상 자만 연구에 참여하였다. 또한, 실험 도중에 통증을 호소 하거나 중도 하차를 결정한 경우, 어떠한 불이익도 없으 며 개인정보와 관련된 어떠한 정보도 공개하지 않을 것을 공지하였다.

\section{평가 방법 및 측정 도구 \\ 수동적 발목가동범위}

발목의 DF-PROM은 측정은 임상경력 5년 이상의 물 리치료사 두 명에 의해 측정되었다. 디지털 듀얼 경사계 (Dualer IQ Digital Inclinometer, J-Tech, U.S.A.)를 이 용하여 발목의 DF-PROM을 측정하였으며, 대상자는 편 안하게 엎드린 상태로 무릎을 $90^{\circ}$ 로 구부린 다음, 주 측 정기는 외측 복사뼈(lateral malleus)에 고정시키고 비골두 (fibular head)와 5번째 종족골이 이루는 각도가 90도를 이룬 상태에서 보초측정계는 비골두 중앙과 연결한 선에 평행을 유지한 채 고정시킨 후 두 측정계의 기울기에 따 라 관절가동범위를 측정하였다. 검사자는 발바닥을 움직 임이 제한될 때까지 배측 굴곡 방향으로 힘을 가하여 발 목의 DF-PROM 측정하였다[14]. 모든 측정은 3회 반복 측정하였고, 평균값을 사용하였다. 본 연구에서 DF-PROM 의 측정자내 신뢰도는 높은 등급(ICC, 0.97)으로 나타났다.

\section{일어서서 걷기 검사}

TUG test는 모든 대상자들이 팔걸이가 있는 $50 \mathrm{~cm}$ 의 자에서 일어나 $3 \mathrm{~m}$ 를 걷고 돌아서서 의자로 돌아와 앉는 시간은 기록한다. 걸린 시간은 스톱워치를 사용하여 초 단위로 측정하였다[15]. 모든 측정은 3 회 반복하여 측정 하였고, 평균값을 사용하였다. 선행연구에서 TUG test의 신뢰도는 높은 신뢰도 등급(ICC, 0.98)으로 보고되어 있 다[16].

\section{동적보행지수}

대상자의 보행에 필요한 기능적인 능력을 측정하기 위 해 DGI를 사용하였으며, DGI는 총 8 가지의 과제로 구성 되어 있다. 걷기, 속도 변경하여 걷기, 걸으면서 좌우로 고개 돌리기, 걸으면서 위아래로 고개 움직이기, 걸으면서 축을 중심으로 돌기, 장애물 넘기, 장애물 돌아서 걷기, 계단 오르내리기로 구성되어 있다. DGI 점수는 0 에서 3 점의 4점 척도로 나타내며, 0 점은 심한 손상 3 점은 정상 능력 수준으로 총 24점 만점으로 이루어지며, 19점 이하 이면 낙상위험이 있음으로, 22점 이상이면 안전하게 이동 
할 수 있는 단계로 해석된다[17]. 총 3회 반복 측정하고, 평균값을 사용하였다. 선행연구에서 $\mathrm{DGI}$ 는 높은 신뢰도 등급(ICC, 0.96)으로 보고되어 있다[17].

\section{중재 방법}

본 연구는 무작위 대조군 시험설계(randomized controlled trial design)가 사용되었으며, 연구 대상자들은 일반적 특 성을 조사한 후 엑셀 프로그램을 이용하여 무작위로 실험 군 12 명과 대조군 12 명으로 배정하였다. 중재와 평가는 개입과 가설에 맹검(blinded)된 검사자 2 명에 의해서 측 정되었다. 중재 시작 1 일 전에 대상자의 일반적인 특성과 DF-PROM, TUG test, 그리고DGI를 측정하였으며, 8 주 간의 중재 종료 후 1 일 후에 같은 방법으로 재평가되었다. 실험군과 대조군 모두 입원 프로그램에 따라 1 일 1 회, 주 6 회, 8 주 동안 재활 치료를 30 분간 시행하였고(스트레칭 10 분, 근력 운동 10 분, 균형 및 보행 훈련 10 분), 재활 치 료의 양과 종류는 두 군간 유사성을 유지하였다. 실험군 은 추가로 주 3회 8주간 self-MWM 추가로 실시하였다 [12]. 실험군은 선 자세에서 마비측 하지를 $12 \mathrm{~cm}$ 높이의 평평한 받침대에 위치한 후 두 번째 발가락과 뒤꿈치 (heel)를 검은색 테이프 중앙에 놓게 하였다. 대상자의 비 마비측 발은 대상자의 뒤쪽 바닥 위치하여 체중지지 자세 와 $40 \mathrm{~cm}$ 의 스트랩(strap)을 당길 수 있도록 고정하였다. 스트랩은 마비측 발의 거골 전면과 내-외측 복사뼈 (malleolus)를 지나 비마비측 발의 중간부위에 팽팽하게 걸치게 하여 self-MWM시 스트랩을 후방으로 당길수 있 도록 하였다. Self-MWM의 시작자세는 스트랩이 팽팽하 게 당겨진 상태에서 대상자의 마비측 무릎을 능동적으로 전방으로 구부려 체중을 마비측 하지로 이동시키다.이때 뒤꿈치가 떨어지지 않도록 유지한다. 20 초 동안 유지하고 원위치로 되돌아와 10 초간 휴식을 취한다. 총 15 회 실시 하며 대상자의 안전을 위해 도움이 필요할 경우 언제든지 안전 바(bar)를 가볍게 잡도록 하였다(figure 1).

\section{자료분석}

본 연구에서 수집된 자료는 윈도우용 SPSS(ver. 18, IBM Corp., USA)을 사용하여 분석하였다. 정규성 검정 입증을 위해 Kolmogorov-Smirnov 검정을 사용하였고, 모든 자료는 평균과 표준편차를 사용하였다. 연구 대상자 들의 일반적인 특성 비교와 그룹 간의 사전 동질성 비교 는 카이 제곱 검정 분석과 독립표본 $\mathrm{t}$-검정(independent t-test)을 사용하였다. 군내 중재 전과 후의 종속변수의 변 화량을 비교하기 위해 대응표본 t-검정(paired t-test)을 사 용하였고, 군간 중재 후 변화량을 비교하기 위해 독립표 본 t-검정을 사용하였다. 통계학적 유의 수준은 $<0.05$

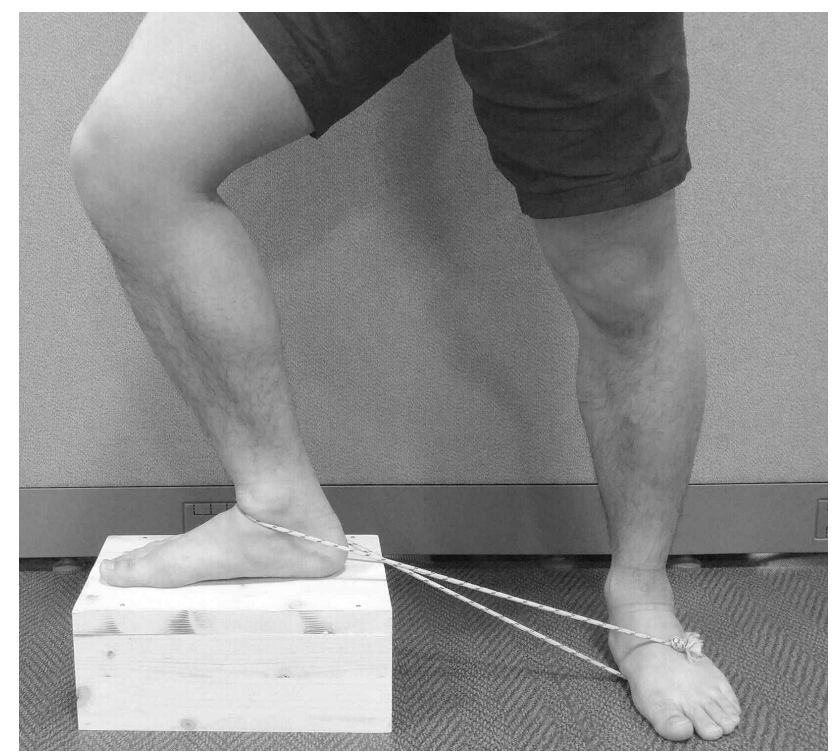

Figure 1. Self-Mobilization with movement

로 하였다.

연구 결과

\section{연구대상지들의 일반적인 특성}

두 군간 동질성 검증 결과 연구 대상자의 일반적 특성 은 모두 동질 한 것으로 나타났으며, 일반적인 특성은 Table 1 과 같다.

\section{발목DF PROM 및' TUG test, 그리고 $D G /$ 측정 결과 비교}

두 군간 발목의 DF-PROM, TUG test, 그리고 DGI 의 비교 결과는 Table 2에 나타나 있다. 중재 전 두 군 간 모든 측정값은 유의한 차이가 없었다 $(\mathrm{p}>0.05)$. self-MWM 적용 후 DF-PROM 및 TUG test, 그리고 $\mathrm{DGI}$ 는 실험군이 대조군보다 유의하게 증가하였다 $(\mathrm{p}<0.05)$. 또한, 두 군의 중재 전과 후의 집단 내 비교 결과, 실험군에서만 DF-PROM 및 TUG test, 그리고 $\mathrm{DGI}$ 가 유의하게 증가하였고 $(\mathrm{p}<.05)$, 대조군은 유의한 차이가 없었다 $(\mathrm{p}>0.05)$.

\section{고찰}

본 연구의 목적은 만성 뇌졸중 환자를 대상으로 발목의 self-MWM의 적용이 DF-PROM, TUG-test, 그리고 DGI 에 미치는 영향에 대해 알아보고자 하였다. Self-MWM의 적용 후, 발목 DF-PROM, TUG test, 그리고 DGI는 대 조군에 비해 유의한 개선이 나타났다. 본 연구 결과 
Table 1. Clinical information of the patients with stroke

\begin{tabular}{|c|c|c|c|}
\hline & self-MWM group & control group & $\mathrm{p}$ \\
\hline \multicolumn{4}{|l|}{$\operatorname{Sex}(n)$} \\
\hline Male/Female & $7 / 5$ & $6 / 6$ & 0.688 \\
\hline \multicolumn{4}{|l|}{ Affected side (n) } \\
\hline Right/Left & $4 / 8$ & $6 / 6$ & 0.418 \\
\hline \multicolumn{4}{|l|}{ Type of stroke (n) } \\
\hline Infarction/ Hemorrhage & $6 / 6$ & $5 / 7$ & 0.688 \\
\hline Onset (month), mean (SD) & $10.8 \pm 2.67$ & $11.2 \pm 2.69$ & 0.707 \\
\hline Age (years), mean (SD) & $61.2 \pm 5.09$ & $60.6 \pm 7.41$ & 0.824 \\
\hline Height $(\mathrm{cm})$, mean (SD) & $167.2 \pm 6.51$ & $163.8 \pm 7.48$ & 0.257 \\
\hline Weight (kg), mean (SD) & $65.8 \pm 9.55$ & $64.7 \pm 9.12$ & 0.779 \\
\hline K-MMSE (scores), mean (SD) & $25.9 \pm 1.62$ & $26.1 \pm 1.92$ & 0.821 \\
\hline
\end{tabular}

Baseline demographic data for patients include in the two different groups and significance level at $p<0.05$ for difference between the groups.

self-MWM: self-mobilization with movement, K-MMSE: Korean-mini mental state examination.

Table 2. Changes in the intervention in each group

\begin{tabular}{llllcc}
\hline & \multicolumn{2}{l}{ self-MWM group $(\mathrm{n}=12)$} & \multicolumn{2}{l}{ control group $(\mathrm{n}=12)$} & \\
\hline Parameters & Pre test & Post test & Pre test & Post test & $\mathrm{p}$ \\
\hline Ankle DF-PROM $\left(^{\circ}\right)$ & $7.08 \pm 0.87$ & $10.56 \pm 1.26^{*}$ & $7.31 \pm 0.71$ & $8.08 \pm 1.45$ & $<0.001^{\dagger}$ \\
TUG test (sec) & $21.91 \pm 3.87$ & $18.01 \pm 3.04^{*}$ & $22.91 \pm 3.76$ & $21.68 \pm 2.31$ & $0.003^{\dagger}$ \\
Dynamic gait index (score) & $17.25 \pm 1.22$ & $19.42 \pm 0.79^{*}$ & $16.75 \pm 1.54$ & $17.01 \pm 1.59$ & $<0.001^{\dagger}$ \\
\hline
\end{tabular}

Values are expressed as mean \pm standard deviation.

DF-PROM: dorsiflexion passive range of motion, TUG test: timed up and go test.

${ }^{*} \mathrm{P}<0.01$ indicateasignificantdifferencebetweenpre-andpost-treatmentswithinthegroup.

${ }^{\dagger} \mathrm{P}<0.01$ indicate a significant difference between the change scores between the groups.

self-MWM의 적용이 만성 뇌졸중 환자의 발목 DF-PROM와 동적균형 그리고 보행기능의 개선에 있어 긍정적인 결과가 나타났다.

본 연구 결과에서 발목의 DF-PROM은self-MWM 중재 적용 후 대조군에 비해 $350.6 \%$ 증가하였다. 체중 지지를 동반한 self-MWM은 스트랩에 의한 경골(tibia) 의 전방 활주를 촉진시키고 발목 관절의 부수적인 관 절 움직임(accessory motion)의 개선과 self-MWM동안 의 능동적이고 반복적인 체중지지를 동반한 런지 (lunge)자세는 발목의 저측 굴곡근(ankle plantar flexors)의 신장을 유도하여 만성 뇌졸중 환자의 발목의 $\mathrm{DF}-\mathrm{PROM}$ 을 증가시켰을 것이다[9, 11]. 또한, self-MWM 동안의 전-후방으로의 경골의 활주(glide)는 비골의 위치 결함을 정상 위치로 회복시킴에 따라 발목
의 운동형상학적(kinematics) 움직임을 개선시켜 발목 의 DF-PROM를 증가시켰을 것이다. 이는 만성 뇌졸중 환자를 대상으로 발목의 $\mathrm{MWM}$ 적용 후 대조군과 체중 지지군과 비교하여 무릎 신전 근력과 발목 DF-PROM, 보행능력의 개선을 확인한 선행연구[18]와 발목의 가동 범위 제한을 가진 만성 뇌졸중 환자를 대상으로 $\mathrm{MWM}$ 테이핑 적용한 결과 발목의 DF-PROM과 보행 기능의 개선을 확인한 선행연구[9]와 동일한 결과를 보였다.

TUG test 시간은 self-MWM 중재 적용 후 대조군에 비해 $219.7 \%$ 감소하였다. 연구 대상자들의 TUG test 시간의 유의한 감소를 통하여 self-MWM의 적용이 동 적 균형 능력을 향상시킨 것을 확인하였다. Self-MWM 동안의 런지자세를 통한 마비측 하지의 반복적인 체중 지지와느린 속도의 발목의 배측 굴곡 움직임은 발목에 
위치한 근육들의 근활성도를 개선시켜 만성 뇌졸중 환 자의 관절 위치 감각과 자세 조절 능력을 향상시켰을 것이다[7, 10]. 또한, Self-MWM은 족저의 힘(plantar force)과 보행시 발뒤꿈치의 접촉 시간을 증가시켜 보 행 속도 및 보폭(step length)을 증가시켜 TUG test 시 간을 감소시키는데 긍정적인 영향을 미쳤을 것으로 사 료된다 $[19,20]$. 이는 만성 뇌졸중 환자 30 명을 대상으 로 체중지지 $\mathrm{MWM}$ 치료군(15명)과 플라시보군(15명) 으로 나누어 비교한 결과, 플라시보군 보다 체중지지 $\mathrm{MWM}$ 치료군에서 발목 관절가동범위, TUG-test, 그리 고 보행 능력이 유의하게 개선되었다는 선행연구[21]와 만성 뇌졸중 환자를 대상으로 거골의 후방 이동을 이 용한 $\mathrm{MWM}$ 적용군(17명)과 체중지지군(17명)을 비교 한 결과 $\mathrm{MWM}$ 적용군이 체중지지군보다 발목 관절가 동범위와 근력, TUG test, 그리고 보행능력이 유의하게 개선되어 나타났다는 선행연구[22]와 동일한 결과를 보 였다.

본 연구 결과에서 DGI는 self-MWM 중재 적용 후 대조군에 비해 $350.6 \%$ 증가하였다. 만성 뇌졸중 환자 의 재활 치료에 있어 보행능력의 개선은 가장 중요한 목표이다. 본 연구에서는 self-MWM의 중재 차이를 평 가하기 위해 DGI를 사용하였으며, DGI는 기능적인 안 정 능력과 함께 낙상위험을 측정하기 위한 평가 도구 로 알려져 있다[17]. 체중지지를 동반한 마비측 하지의 self-MWM 적용은 발목 DF-PROM과 발목 안정성의 증가로 나타나 보행시 하지의 움직임을 개선시켜 축을 중심으로 돌기 및 장애물 넘기 그리고 계단 오르내리 기 등의 능력을 향상시켰다고 생각한다 $[9,18]$. 또한, self-MWM의 적용은 마비측 하지의 입각기에서 발뒤 꿈치 떼기(heel-off) 시간 증가[19]와 발목의 고유수용 성 감각의 개선[23]은 자세 조절 능력 증가로 나타나 보행 속도 향상과 장애물 대처 능력 증가로 타나 DGI 점수에 긍정적인 영향을 미쳤을 것이다. 이는 만성 뇌 졸중 환자를 대상으로 마비측 하지의 $\mathrm{MWM}$ 을 주 5회 4주간 실시한 결과 대상자의 발목의 배측 굴곡 관절 움직임, 균형 능력, TUG-test, 그리고 DGI 점수가 개선 되었다는 선행 연구[21]와 발목 배측 굴곡에 제한이 있 는 만성 뇌졸중 환자 26 명을 대상으로 움직임을 동반 한 발목 가동 테이핑 적용 후 발목 DF-PROM과 보행 속도, 분속수, 그리고 $\mathrm{DGI}$ 를 측정한 결과 모든 항목에 서 유의하게 향상되어 나타났다는 선행연구와 동일한 결과를 보였다[24].

본 연구에서 수정, 보완되어야 할 제한점이 존재한다. 첫째, 실험에 참가한 대상자는 모두 24명으로, 연구 대상 자 수의 검정력 분석결과 효과크기가 1.19 로 나타났지만 본 연구 결과를 모든 뇌졸중 환자에게 일반화 시키기에는
부족함이 있다. 둘째, 본 연구는 self-MWM의 중재 전과 후의 효과만 조사하였고 추적 관찰이 이루어 지지 않았다. 추후 연구에서는 장기간의 훈련 효과를 입증할 수 있는 연구가 진행되어야 할 것이다.

\section{결론}

발목의 관절가동범위 제한이 있는 만성 뇌졸중 환자에 게 self-MWM의 적용이 발목 DF-PROM 및 TUG test, 그리고 DGI에 미치는 영향을 알아보고자 하였다. 연구결과, self-MWM 적용 후 대조군과 비교하여 발목 DF-PROM 및 TUG test, 그리고 DGI가 유의하게 개선되어 나타났 다. 결론적으로 만성 뇌졸중 환자에 있어 self-MWM의 적용은 발목의 움직임 및 동적 균형과 보행능력에 긍정적 인 영향을 미치는 것을 알 수 있었다.

\section{참고문헌}

1. Mirbagheri MM, Ladouceur $\mathrm{M}$, Barbeau $\mathrm{H}$, Kearney RE. The effects of long-term FES-assisted walking on intrinsic and reflex dynamic stiffness in spastic spinal-cord-injured subjects. IEEE Trans Neural Syst Rehabil Eng. 2002;10(4):280-9.

2. Geiger RA, Allen JB, O'Keefe J, Hicks RR. Balance and mobility following stroke: effects of physical therapy interventions with and without biofeedback/forceplate training. Phys Ther. 2001;81(4): 995-1005.

3. Saltzman CL, Nawoczenski DA. Complexities of foot architecture as a base of support. J Orthop Sports Phys Ther. 1995;21(6):354-60.

4. Chung SG, Van Rey E, Bai Z, Roth EJ, Zhang L-Q. Biomechanic changes in passive properties of hemiplegic ankles with spastic hypertonia. Arch Phys Med Rehabil. 2004;85(10):1638-46.

5. Langhorne P, Coupar F, Pollock A. Motor recovery after stroke: a systematic review. Lancet Neurol. 2009;8(8):741-54.

6. Divani AA, Vazquez G, Barrett AM, Asadollahi M, Luft AR. Risk factors associated with injury attributable to falling among elderly population with history of stroke. Stroke. 2009;40(10):3286-92.

7. Gao F, Ren Y, Roth EJ, Harvey R, Zhang L-Q. Effects of repeated ankle stretching on calf muscletendon and ankle biomechanical properties in stroke survivors. Clin Biomech. 2011;26(5):516-22. 
8. de Wit DC, Buurke J, Nijlant JM, IJzerman MJ, Hermens HJ. The effect of an ankle-foot orthosis on walking ability in chronic stroke patients: a randomized controlled trial. Clin Rehabil. 2004;18(5): 550-7.

9. Park D, Cynn H-S. Effects of walking with talus-stabilizing taping on passive range of motion, timed up and go, temporal parameters of gait, and fall risk in individuals with chronic stroke: a cross-sectional study. J Manipulative Physiol Ther. 2021;44(1):49-55.

10. Collins N, Teys P, Vicenzino B. The initial effects of a Mulligan's mobilization with movement technique on dorsiflexion and pain in subacute ankle sprains. Man Ther. 2004;9(2):77-82.

11. Vicenzino B, Branjerdporn M, Teys P, Jordan K. Initial changes in posterior talar glide and dorsiflexion of the ankle after mobilization with movement in individuals with recurrent ankle sprain. $\mathrm{J}$ Orthop Sports Phys Ther. 2006;36(7):464-71.

12. Jeon I-c, Kwon O-y, Yi C-H, Cynn H-S, Hwang U-j. Ankle-dorsiflexion range of motion after ankle self-stretching using a strap. J Athl Train. 2015;50(12): 1226-32.

13. An C-M, Jo S-O. Effects of talocrural mobilization with movement on ankle strength, mobility, and weight-bearing ability in hemiplegic patients with chronic stroke: a randomized controlled trial. J Stroke Cerebrovasc Dis. 2017;26(1):169-76.

14. Hong W-S, Kim K-W. Reliability of measurement devices for measuring the ankle joint motion. Korean J Orthop Manu Ther. 2009;15(1):1-8.

15. Park D, Lee K-S. Effects of talus stabilization taping versus ankle kinesio taping in patients with chronic stroke: a randomized controlled trial. J Exerc Rehabil. 2019;15(6):775-80.

16. Alghadir AH, Al-Eisa ES, Anwer S, Sarkar B. Reliability, validity, and responsiveness of three scales for measuring balance in patients with chronic stroke. BMC neurology. 2018;18(1):1-7.

17. Jonsdottir J, Cattaneo D. Reliability and validity of the dynamic gait index in persons with chronic stroke. Arch Phys Med Rehabil. 2007;88(11):1410-5.

18. An C-M, Won J-I. Effects of ankle joint mobilization with movement and weight-bearing exercise on knee strength, ankle range of motion, and gait velocity in patients with stroke: a pilot study. J Phys Ther Sci. 2016;28(2):689-94.

19. Kang M-h, Kim J-w, Choung S-d, Park K-n, Kwon $\mathrm{O}-\mathrm{y}, \mathrm{Oh} \mathrm{J}-\mathrm{s}$. Immediate effect of walking with talus-stabilizing taping on ankle kinematics in subjects with limited ankle dorsiflexion. Phys Ther Sport. 2014;15(3):156-61.

20. Yoon J-y, Hwang Y-i, An D-h, Oh J-s. Changes in kinetic, kinematic, and temporal parameters of walking in people with limited ankle dorsiflexion: pre-post application of modified mobilization with movement using talus glide taping. J Manipulative Physiol Ther. 2014;37(5):320-5.

21. Kim S-L, Lee B-H. The effects of posterior talar glide and dorsiflexion of the ankle plus mobilization with movement on balance and gait function in patient with chronic stroke: A randomized controlled trial. J Neurosci Rural Pract. 2018;9(01):061-7.

22. Lee J, Kim J-O, Lee B-H. The effects of posterior talar glide with dorsiflexion of the ankle on mobility, muscle strength and balance in stroke patients: a randomised controlled trial. J Phys Ther Sci. 2017;29(3):452-6.

23. Hopper D, Samsson K, Hulenik T, Ng C, Hall T, Robinson K. The influence of Mulligan ankle taping during balance performance in subjects with unilateral chronic ankle instability. Phys Ther Sport. 2009;10(4):125-30.

24. Park D-H, Kang T-W, Lee K-S. Effects of Ankle Mobilization with Movement Taping on Ankle Range of Motion and Gait Functions in Patients with Chronic Stroke with Limited Ankle Dorsiflexion. Kor J Neuromuscul Rehabil. 2020;10(2):48-56. 